Responsiveness, If You Can Afford It:

Policy Responsiveness in Good and Bad Economic Times

\author{
Lawrence Ezrow \\ Professor and Head \\ Department of Government \\ University of Essex \\ Colchester CO4 3SQ \\ United Kingdom \\ ezrow@essex.ac.uk \\ Timothy Hellwig \\ Professor \\ Department of Political Science \\ Indiana University \\ 1100 E. Third Street \\ Bloomington, IN 47401 \\ thellwig@indiana.edu \\ Michele Fenzl \\ $\mathrm{PhD}$ Candidate \\ Department of Government \\ University of Essex \\ Colchester CO4 3SQ \\ United Kingdom \\ mfenzl@essex.ac.uk
}




\title{
Responsiveness, If You Can Afford It: Policy Responsiveness in Good and Bad Economic Times
}

\begin{abstract}
Traditional theories of representation posit that political parties have incentives to respond to public opinion which, in turn, is reflected in public policy as parties come together to form governments. Absent from this chain of representation, however, is the notion of costs. We advance the study of policy responsiveness by arguing that the government's cost of responding to the electorate is marginal under conditions of strong economic growth but considerable during hard economic times. Cross-national analyses of voters and government welfare policies produces results that are consistent with this expectation. The findings imply that democratic performance, expressed as responsiveness, is conditional on economic growth.
\end{abstract}

Keywords: government responsiveness, economic decline, party behavior, welfare spending, representation

Running header title: Responsiveness, If You Can Afford It

Supplementary material for this article is available in an online appendix accessible from the JOP website. Data and replication files are available from Dataverse:

https://dataverse.harvard.edu/dataverse/jop. 
Representative democracy means that voters choose leaders to represent them in substantive terms. On this point, the weight of the evidence from industrialized democracies finds that elected representatives and the governments they form are responsive to the public's preferences (Budge et al. 2012; Erikson et al. 2002; Kang and Powell 2010; Soroka and Wlezien 2010; but see Achen and Bartels 2016). But while models of government responsiveness necessarily emphasize the influence of public sentiment, policy and performance outcomes in contemporary democracies are, of course, shaped by a range of factors. Some studies examine how responsive government bears on policy outcomes like taxes, interest rates, social spending, or pension reform (e.g., Häusermann 2010; Kang and Powell 2010; Budge et al. 2012). Delving deeper, researchers identify the circumstances shaping these arrangements, including whether the opinion-policy link varies according to electoral systems, power-sharing arrangements, and federalism (Soroka and Wlezien 2010; Peters 2016).

The common refrain running through these studies is that the degree to which elitecrafted policy reflects mass sentiment depends on the larger institutional environment. Certain institutional arrangements facilitate policy responsiveness, and others slow, blunt, or otherwise impede it. Missing from previous studies on the impact of institutional arrangements, however, is something even more basic to politics: the notion of costs. Students of public opinion have long recognized that citizens balance the benefits of government action (for, say better health care) against the costs incurred (higher taxes). And recently, motivated by the fall-out of the 2008 financial crisis, the political parties research has considered how the economic situation influences party behavior. ${ }^{1}$

\footnotetext{
${ }^{1}$ Recent studies examine the effects of economic crises on party behavior. Traber, Giger, and Häusermann (forthcoming) argue that while voters care about the economy in times of crisis, (governing) parties wish to downplay the issue - thus producing a salience gap between political elites and voters. Clements, Nanou, and Real-Dato (2018) find that (governing) parties
} 
In this article we argue that the responsiveness of policy to public opinion is not inevitable but instead depends on costs, as conscribed by the health of the nation's economy. From this systematic consideration of costs follows an important new expectation: Governments are more responsive to public preferences when the economy is performing well and less when it is not. We evaluate this simple but untested claim using data on government welfare state spending, median voter preferences, and the performance of the economy across fourteen developed democracies from 1978 to 2010, a period that spans a wide range of economic experiences. Encouragingly, we find in the main that governments in these western democracies deliver policy in response to shifts in voter preferences. Yet this responsiveness is stronger in magnitude under robust economic conditions. Conversely, anemic economies suppress government responsiveness to public opinion.

\section{Explaining Government Policy Choices: Two Research Traditions}

What explains government policy decisions? Two literatures address this question: research on policy responsiveness, and research on the political economy of the welfare state. The former asserts that government policy choices are informed by the preferences of the electorate and emphasizes the importance of the chain of representation linking citizens to policy outcomes. This chain begins with voters selecting parties to represent their interests. Parties-in-parliaments then come together to form a government. Conflicts among factions and parties must then be overcome to advance a coherent set of policy objectives. Finally, the government implements its objectives in the form of concrete policy solutions that reflect

are less responsive to voters relative to the preferences of market elites. From a different perspective, analyses performed by Abou-Chadi and Kayser (2017) suggest that voters demand less during periods of economic decline. These studies are different than ours in that they focus on issue salience, party position-taking behavior (as opposed to policies), or are limited to the crisis years. 
citizens' preferences. The responsiveness of policy makers to the median voter thus risks derailment at numerous points along this multistage process. Research on party responsiveness has explored the contexts in which the transmission from citizen preferences to policy outputs is facilitated or impeded (Kang and Powell 2010; Soroka and Wlezien 2010). Further, governments may not tend equally to all voters' preferences but favor some subconstituencies over others (Griffin and Newman 2005; Rosset, Giger, and Bernauer 2013); nor is responsiveness constant across issues (Rasmussen, Reher, and Toshkov forthcoming). These caveats aside, the basic conclusion is that responsiveness to the median voter works.

The literature on the political economy of the welfare state emphasizes a different and wider set of factors to understand the bases of government policy. A venerable tradition argues that government partisanship along with the power of labor provides a parsimonious account of policy outcomes (Stephens 1979). Others take a more institutional approach and assert that policy outcomes vary according to long-standing relationships among businesses, financial institutions, workers, and governments (Hall and Soskice 2000). Still another strand of this research highlights how the organization of the macro-economy puts pressure on governments to compensate those adversely affected by globalization, deindustrialization, and other changes associated with advanced capitalism (Iversen and Cusack 2000).

The policy responsiveness and political economy literatures, then, provide very different accounts of government policy decisions. The former highlights how party incentives facilitate responsiveness to the median voter; the latter emphasizes how capitalism's structural factors limit the government's options and assigns little independent role to voters or their party representatives. ${ }^{2}$ This matters for how we understand policy change. The first tradition

\footnotetext{
${ }^{2}$ An exception is Brooks and Manza's (2007) work on how cross-national differences in the size of welfare states are shaped by differences in the opinions of national electorates. However, while Brooks and Manza examine public opinion-spending linkages, they do not con-
} 
implies that policy change is a consequence of changing voter preferences; the latter tradition predicts change to be more evolutionary in nature and dependent on constraints. Of utmost importance for our contribution, the parties scholarship downgrades (if not ignores) the potential costs of policy responsiveness, while the comparative welfare state literature emphasizes structural constraints, or costs, with voters left to the side. We combine insights from these contributions by recognizing that economic downturns reduce public revenues, raising policymakers' pressures to return to acceptable levels of economic growth while stymying their capacity to respond to voter preferences. ${ }^{3}$ This generates the following hypothesis: government policy responsiveness to public opinion is stronger when economic conditions are robust and weaker during lean economic times.

\section{Measures and Data}

We evaluate this claim by examining the determinants of government policy. Data on our key measures are available on an annual basis from 1978 to 2010 for fourteen developed democracies: Austria, Belgium, Denmark, Finland, France, Germany, Greece, Ireland, Italy, the Netherlands, Portugal, Spain, Sweden, and the United Kingdom. Testing our hypothesis requires measures for three central concepts: policy outcomes, public opinion, and economic conditions. In the set of Western democracies we analyse, social welfare is the most salient dimension of policy contestation. ${ }^{4}$ Accordingly, our dependent variable is measured using the social welfare generosity index developed by Scruggs, Jahn, and Kuitto (2017). This in-

sider responsiveness per se (in terms of shifts in spending) nor do they consider variations in the welfare state-public opinion nexus across good and bad economic times.

${ }^{3}$ The supplementary information file extends this theoretical discussion in terms of government's valence and positional considerations in good and bad economic times.

${ }^{4}$ Analyses of party policy positions in Western Europe find that the tax-spend dimension ranks highest in terms of importance (Benoit and Laver 2006, esp. p. 176 and appendix). 
dex, Welfare state generosity, is comprised of a broad range of social insurance benefits including employment insurance, sick pay insurance, and public pensions. ${ }^{5}$ While an annual measure of public preferences for social welfare would be ideal for our purposes, such measures do not exist cross-nationally. Accordingly, for Median voter position on policy preferences we rely on the left-right scale from 1 (left) to 10 (right). We use surveys from the Eurobarometer series to calculate the median positions for each country-year. We note that several scholars have analyzed the relationship between redistributive attitudes and LeftRight self-placements, and they report strong estimates of this relationship (Alesina and Giuliano 2009; Benoit and Laver 2006). Our third variable of interest, Economic growth, is measured in real terms using data provided in Armingeon et al. (2017). ${ }^{6}$

We use a general baseline specification to assess the direct influences of public opinion and the economy on policy outcomes and then move to assess whether the economy conditions the effects of public opinion. Given our annual data, we specify a model which allows the analyst to uncover both the immediate and long-run impact of a shock to $X$ on $Y$. To do so, we specify an error correction model (ECM) of the form $\Delta Y_{i t}=\alpha_{0}+\alpha_{1} Y_{i t-1}+\beta_{0} \Delta X_{i t}+$

\footnotetext{
${ }^{5}$ The index is the sum of the sub-indices for unemployment and sick pay insurance and pension generosity. Country-year values are based on $z$-scores for all available observations for each characteristic. Proponents of this measure argue that it is a better measure of government policy than social welfare spending because the latter is influenced by unemployment rates and the population of pensioners that cause welfare spending to vary even if entitlement policies remain the same.

${ }^{6}$ Real economic growth accounts for inflation. We also control for membership in the European Monetary Union and for the size of the labor force (Armingeon et al. 2017; Visser 2015). The supplementary information file reports the robustness of our results over time trends, debt levels, current account balances, and for a set of political institutions.
} 
$\beta_{1} X_{i t-1}+\varepsilon_{i t}$, where $\Delta$ is the difference operator, $t$ indexes time (in years), and $i$ countries. Modeling shifts in policy outcomes rather than levels helps address potential issues of nonrandom error structures (Tromborg 2014). The contemporaneous impact of a shock to $X$ is provided by $\beta_{0}$ while the cumulative impact is $\beta_{1} / \alpha_{1}$ (De Boef and Keele 2008). ${ }^{7}$ To address serial correlation and to allow for inter-panel differences in the dynamic processes we estimate AR(1) terms. Finally, we include country fixed effects to account for unmeasured sources of country-level heterogeneity and panel-corrected standard errors to address heteroscedasticity.

Model 1 of Table 1 reports regression estimates. In this model, our chief interest is in the influence of Median voter position on Welfare state generosity. A negative coefficient implies responsiveness: if the median voter is moving rightward and increasing in value, this suggests that welfare state generosity should decrease. Model 1 shows that the coefficient on Median voter position is statistically significant over the long-run. The coefficient on the long run effect for the lagged Median voter position variable is precisely estimated negative 0.35. This result of general responsiveness to public opinion shifts is consistent with previous research (e.g., Budge et al. 2012; Kang and Powell 2010; Soroka and Wlezien 2010). In particular, the results that support longer-term effects, as opposed to more immediate effects, are consistent with research arguing there are significant lags in time between changes in public opinion and subsequent changes in policy outcomes (Budge et al. 2012).

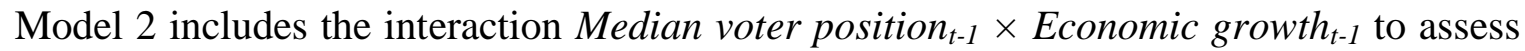
whether this effect of public opinion on welfare state generosity differs across levels of growth. Recall that we expect responsiveness to be greater - that is, the negative influence of Median voter position on Welfare state generosity to be larger-when the economy is grow-

\footnotetext{
${ }^{7}$ Research on ECMs argues that the order of integration must be consistent across variables (Grant and Lebo 2016). For our case, our series are stationary, or balanced with I(0).
} 
ing at a healthy rate. The negative coefficient on the interaction term indicates that growth rates increase the impact of public opinion on government policy.

Using Model 2 estimates, we illustrate the conditioning influence of the economy on responsiveness in two ways. Figure 1A presents the marginal effects for the long-term across the sample range of values for growth. We see that responsiveness occurs only when growth is sufficiently high (approximately 1\%). Figure 1B provides a dynamic representation of this effect. The figure displays a forecast of the change in Welfare state generosity when the median voter position shifts one standard deviation to the left (see SI file for details). As we would expect, a leftward opinion shift increases welfare generosity when growth rates are at or above the sample median of $2.5 \%$ per annum. But when the economy is stagnant, positions of the median voter register no effect on policy.

[Table 1 and Figure 1 here]

\section{Conclusion}

A consensus has emerged in the cross-national research that the quality of democratic representation is influenced by (largely time invariant) political institutions. Our study sheds light on something more fundamental to democratic performance: the notion of costs. Combining insights from studies of party competition and from the political economy of the welfare state, we argue that the government's responsiveness to the public depends on economic conditions. We find that governments in Western democracies are generally responsive to shifts in public opinion. Yet when growth rates fall below one percent per annum, estimates of long-run policy responsiveness become statistically indistinguishable from zero. This finding suggests that economic growth and government responsiveness operate in tandem. And if countries' economies are as interconnected as some argue, then one would expect economic waves of expansion and depression to produce corresponding "waves" of democratic responsiveness. We conclude there exists a minimum threshold of growth that is neces- 
sary for systematic government policy responsiveness. If the degree of economic volatility experienced during the Great Recession returns, we can expect that governments will find the costs of responding to public demands higher than they can bear. Future research should extend these analyses to examine whether what we uncover for welfare policy in general persists for specific policy areas such as immigration and the environment.

\section{Acknowledgements}

We would like to thank Jim Adams, Pablo Fernandez-Vasquez, David Fortunato, Cyanne Loyle, Yana Mommadova, and Will Winecoff for helpful comments on previous versions. We also thank our anonymous reviewers for their feedback. A previous version was presented at the World Politics Research Seminar, Indiana University.

\section{References}

Abou-Chadi, Tarik, and Mark A. Kayser. 2017. “It's Not Easy Being Green: Why Voters Punish Parties for Environmental Policies during Economic Downturns.” Electoral Studies 45(2):201-207.

Achen, Christopher H., and Larry M. Bartels. 2016. Democracy for Realists: Why Elections Do Not Produce Responsive Government. Princeton: Princeton University Press.

Armingeon, Klaus, Virginia Wenger, Fiona Wiedemeier, Christian Isler, Laura Knöpfel, David Weisstanner and Sarah Engler. 2017. Comparative Political Data Set 1960-2014. Bern: Institute of Political Science, University of Berne.

Benoit, Kenneth, and Michael Laver. 2006. Party Policy in Modern Democracies. London: Routledge.

Brooks, Clem, and Jeff Manza. 2007. Why Welfare States Persist. Chicago: University of Chicago Press. 
Budge, Ian, Hans Keman, Michael D. McDonald, and Paul Pennings. 2012. Organizing Democratic Choice: Party Representation Over Time. Oxford: Oxford University Press.

Clements, Ben, Kyriaki Nanou, and José Real-Dato. 2018. "Economic Crisis and Party Responsiveness on the Left-Right Dimension in the EU." Party Politics 24(1): 52-64.

De Boef, Suzanna, and Luke Keele. 2008. "Taking Time Seriously.” American Journal of Political Science 52(1):184-200.

Erikson, Robert S., Michael B. Mackuen, and James A. Stimson. 2002. The Macro Polity. Cambridge: Cambridge University Press.

Grant, Taylor, and Matthew J. Lebo. 2016. "Error Correction Methods with Political Time Series." Political Analysis 24(1): 3-30.

Griffin, John D., and Brian Newman. 2005. “Are Voters Better Represented?” The Journal of Politics 67(4):1206-27.

Iversen, Torben, and Thomas R. Cusack. 2000. "The Causes of Welfare State Expansion: Deindustrialization or Globalization?" World Politics 52: 313-349.

Häusermann, Silja. 2010. The Politics of Welfare State Reform in Continental Europe. New York: Cambridge University Press.

Kang, Shin-Goo, and G. Bingham Powell, Jr. 2010. "Representation and Policy Responsiveness: The Median Voter, Election Rules, and Redistributive Welfare Spending.” Journal of Politics 72(4): 1014-28.

Peters, Yvette. 2016. “The Politics of Representation.” Paper prepared for presentation at the “Stein Rokkan's Heritage” Workshop, Bergen, Norway, September 20-21, 2016.

Rasmussen, Anne, Stefanie Reher, and Dimiter Toshkov. Forthcoming. "The OpinionPolicy Nexus in Europe and the Role of Political Institutions." European Journal of Political Research. 
Rosset, Jan, Nathalie Giger, and Julian Bernauer. 2013. "More Money, Fewer Problems?" West European Politics 36(4):817-835.

Scruggs, Lyle, Detlef Jahn, and Kati Kuitto. 2017. “Comparative Welfare Entitlements Dataset 2. Version 2017-09.” University of Connecticut \& University of Greifswald.

Soroka, Stuart, and Christopher Wlezien. 2010. Degrees of Democracy: Politics, Public Opinion, Policy. Cambridge: Cambridge University Press.

Stephens, John D. 1979. The Transition from Capitalism to Socialism. London: Macmillan.

Traber, Denise, Giger, Nathalie, and Silja Häusermann. Forthcoming. "How Economic Crises Affect Political Representation: Declining Party-Voter Congruence in Times of Constrained Government." West European Politics.

Tromborg, Mathias Wessel. 2014. "Bringing the Median Voter Back in.” Journal of European Social Policy 24(2): 107-121.

Visser, Jelle. 2015. ICTWSS: Database on Institutional Characteristics of Trade Unions, Version 5. Amsterdam Institute for Advanced Labour Studies.

Williams, Laron K., and Guy D. Whitten. 2011. "Dynamic Simulations of Autoregressive Relationships.” Stata Journal 11(4): 577-588.

\section{BIOGRAPHICAL STATEMENT:}

Lawrence Ezrow is Professor and Head in the Department of Government at the University of Essex, Colchester, CO4 3SQ, United Kingdom.

Timothy Hellwig is Professor of Political Science at Indiana University, Bloomington, IN 47401

Michele Fenzl is a PhD Candidate in the Department of Government at the University of Essex, Colchester, CO4 3SQ, United Kingdom. 
Table 1. Analyses of Changes in Welfare State Generosity

\begin{tabular}{|c|c|c|c|c|}
\hline \multirow[b]{2}{*}{ Variables } & \multicolumn{2}{|c|}{ Model 1} & \multicolumn{2}{|c|}{ Model 2} \\
\hline & Coeff. & S.E. & Coeff. & S.E. \\
\hline Welfare state generosity $y_{t-1}$ & $-0.099 * * *$ & $(0.015)$ & $-0.098 * * *$ & $(0.015)$ \\
\hline$\Delta$ Median voter position ${ }_{t}$ & -0.162 & $(0.171)$ & -0.133 & $(0.170)$ \\
\hline Median voter position $_{t-1}$ & $-0.347 * * *$ & $(0.111)$ & -0.165 & $(0.130)$ \\
\hline$\Delta$ Economic growth $_{t}$ & 0.014 & $(0.010)$ & 0.013 & $(0.010)$ \\
\hline Economic growth $_{t-1}$ & $0.023^{* *}$ & $(0.010)$ & $0.305^{* *}$ & $(0.143)$ \\
\hline$\Delta$ Median voter position ${ }_{t} \times \Delta$ Economic growth ${ }_{t}$ & & & -0.081 & $(0.094)$ \\
\hline 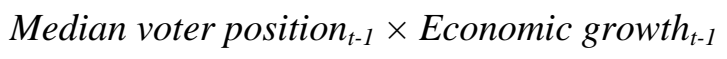 & & & $-0.053 * *$ & $(0.027)$ \\
\hline$\Delta$ Labor force $_{t}$ & 0.052 & $(0.059)$ & 0.053 & $(0.058)$ \\
\hline Labor force $e_{t-1}$ & $-0.059 * * *$ & $(0.015)$ & $-0.053 * * *$ & $(0.016)$ \\
\hline EMU membership & $0.343 * * *$ & $(0.059)$ & $0.333 * * *$ & $(0.059)$ \\
\hline Constant & $5.183 * * *$ & $(0.816)$ & $4.187 * * *$ & $(0.923)$ \\
\hline$R^{2}$ & 0.15 & & 0.15 & \\
\hline
\end{tabular}

Notes. Entries show estimated coefficients, with panel corrected standard errors in parentheses.The dependent variable is $\Delta$ Welfare state generosity. Country dummies are included and omitted from table. Number of observations $=367$, Number of countries $=14, * * * p<0.01, * * p<0.05, * p<0.10$ 
Figure 1. Government Responsiveness in Good and Bad Times

A. Marginal Effect of Median Voter Position on Welfare State Generosity as Economic Growth varies

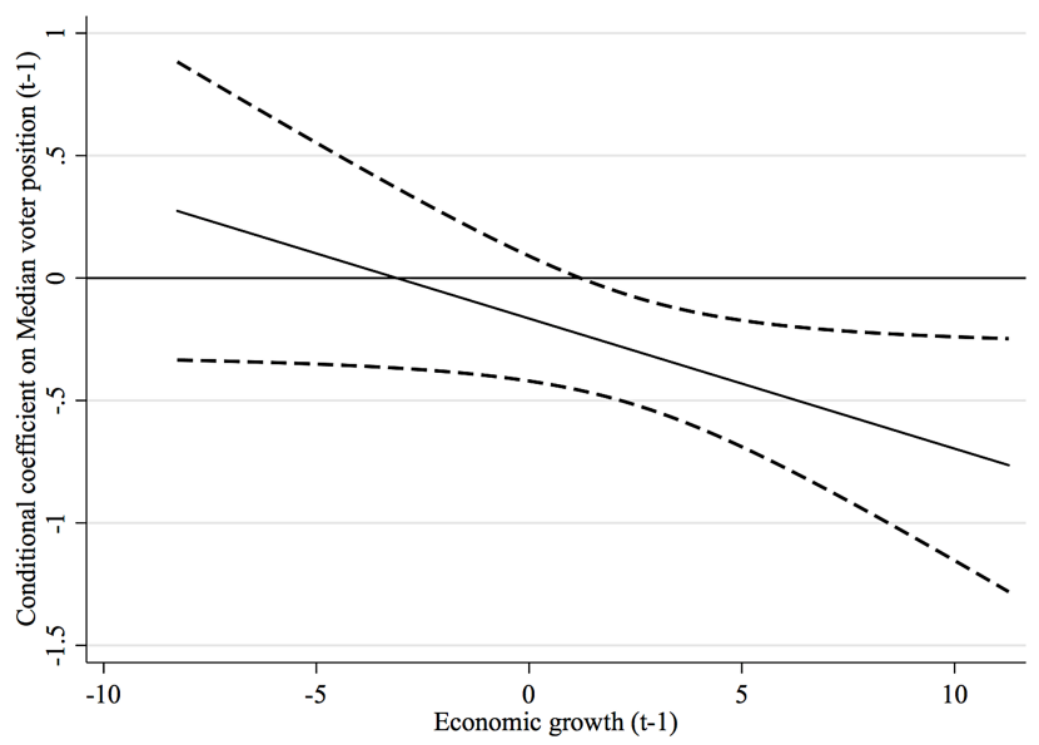

B. Forecast of Effect of Leftward Shift in Median Voter Position on Welfare State Generosity for High, Average, and Zero Rates of Economic Growth

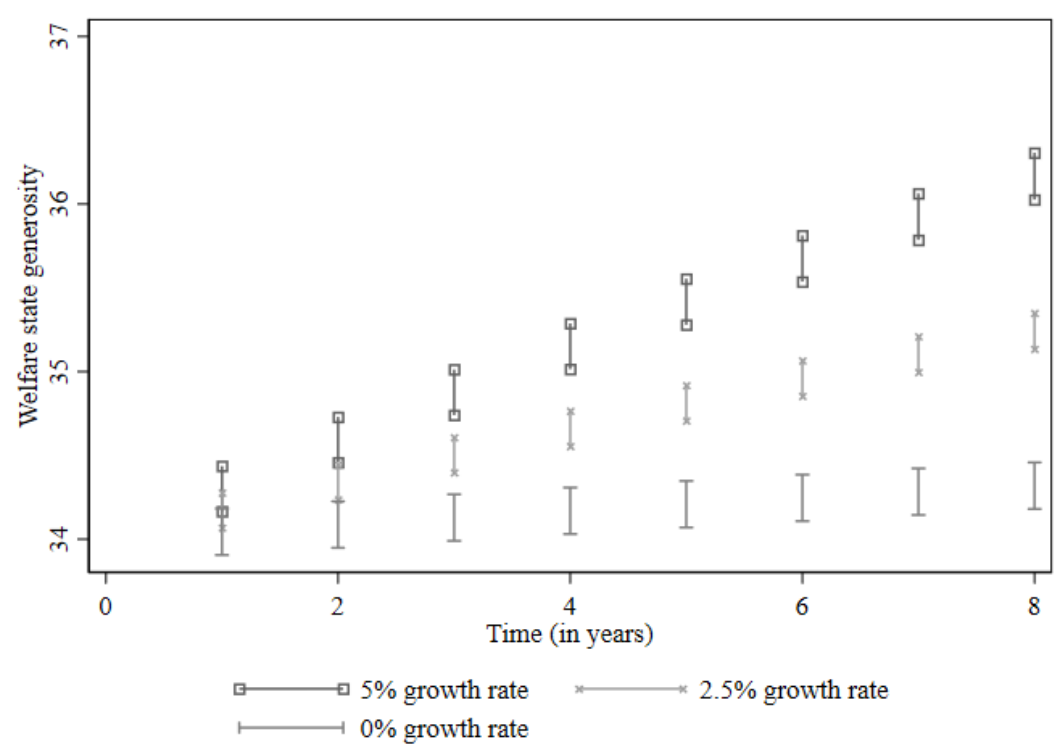

Figures produced with Table 1 Model 2 estimates. Figure 1A charts the coefficient on Median voter position t-1 $_{t-1}$ over values of Economic growth $_{t-1}$. Negative estimates in Figure 1A indicate stronger government responsiveness to public opinion. Dashed lines report $95 \%$ confidence intervals.

Figure 1B displays forecasted expected values of Welfare state generosity when the Median voter position is one standard deviation to the left of its in-sample mean, calculated under three different growth scenarios. Initial value for Welfare state generosity is 34 . Vertical bars report $95 \%$ confidence intervals. Simulations are performed with "dynsim" (Williams and Whitten 2011). 